OPEN ACCESS

Edited by:

Isaias Glezer,

Federal University of São Paulo, Brazil

Reviewed by:

Taisen Iguchi,

National Institute for Basic

Biology, Japan

Patrick Balaguer,

Institut National de la Santé et de la

Recherche Médicale

(INSERM), France

${ }^{*}$ Correspondence:

Lunan Wang

Inwang@nccl.org.cn

Ming Liu

liuming3222@bjhmoh.cn

Fei Xiao

xiaofei3965@bjhmoh.cn

Specialty section:

This article was submitted to

Cellular Endocrinology,

a section of the journal

Frontiers in Endocrinology

Received: 23 December 2019 Accepted: 10 March 2020

Published: 31 March 2020

Citation:

Ji H, Li Y, Liu Z, Tang M, Zou L, Su F, Zhang Y, Zhang J, Li H, Li L, Ai B, Ma J, Wang L, Liu M and Xiao F

(2020) Quantitative Evaluation of the Transcriptional Activity of Steroid Hormone Receptor Mutants and

Variants Using a Single Vector With Two Reporters and a Receptor Expression Cassette.

Front. Endocrinol. 11:167. doi: 10.3389/fendo.2020.00167

\title{
Quantitative Evaluation of the Transcriptional Activity of Steroid Hormone Receptor Mutants and Variants Using a Single Vector With Two Reporters and a Receptor Expression Cassette
}

\begin{abstract}
Huimin $\mathrm{Ji}^{1,2,3}$, Ying $\mathrm{Li}^{3,4}$, Zhao $\mathrm{Liu}^{5}$, Min Tang ${ }^{6}$, Lihui Zou ${ }^{4}$, Fei Su ${ }^{7}$, Yaqun Zhang ${ }^{8}$, Junhua Zhang ${ }^{4}$, Hexin $\mathrm{Li}^{7}$, Lin $\mathrm{Li}^{6}$, Bin $\mathrm{Ai}^{6}$, Jie Ma ${ }^{9,10}$, Lunan Wang ${ }^{1,2,3 *}$, Ming Liu ${ }^{8 *}$ and Fei Xiao ${ }^{4,7,11 *}$
\end{abstract}

${ }^{1}$ National Center for Clinical Laboratories, Beijing Hospital, National Center of Gerontology, Institute of Geriatric Medicine, Chinese Academy of Medical Sciences, Beijing, China, ${ }^{2}$ Beijing Engineering Research Center of Laboratory Medicine, Beijing Hospital, Beijing, China, ${ }^{3}$ Graduate School, Peking Union Medical College, Chinese Academy of Medical Sciences, Beijing, China, ${ }^{4}$ The Key Laboratory of Geriatrics, Beijing Institute of Geriatrics, Beijing Hospital, National Center of Gerontology, National Health Commissions, Institute of Geriatric Medicine, Chinese Academy of Medical Sciences, Beijing, China, ${ }^{5}$ Department of Thyroid and Breast Surgery, The Affiliated Hospital of Xuzhou Medical University, Xuzhou, China,

${ }^{6}$ Department of Oncology, Beijing Hospital, National Center of Gerontology, Institute of Geriatric Medicine, Chinese Academy of Medical Sciences, Beijing, China, ${ }^{7}$ Clinical Biobank, Beijing Hospital, National Center of Gerontology, Institute of Geriatric Medicine, Chinese Academy of Medical Sciences, Beijing, China, ${ }^{8}$ Department of Urology, Beijing Hospital, National Center of Gerontology, Institute of Geriatric Medicine, Chinese Academy of Medical Sciences, Beijing, China, ${ }^{9}$ Center for Biotherapy, Beijing Hospital, National Center of Gerontology, Institute of Geriatric Medicine, Chinese Academy of Medical Sciences, Beijing, China, ${ }^{10}$ State Key Lab of Molecular Oncology, National Cancer Center, Chinese Academy of Medical Sciences and Peking Union Medical College, Beijing, China, " Institute of Geriatric Medicine, Chinese Academy of Medical Sciences, Beijing, China

Although the rapid development of high-throughput sequencing has led to the identification of a large number of truncated or mutated steroid hormone receptor (SHR) variants, their clinical relevance remains to be defined. A platform for functional analysis of these SHR variants in cells would be instrumental for better assessing their impact on normal physiology and SHR-associated diseases. Here we have developed a new reporter system that allows rapid and accurate assessment of the transcriptional activity of SHR variants in cells. The reporter is a single construct containing a firefly luciferase reporter gene, whose expression is under the control of a promoter with multiple steroid hormone responsive elements, and a Renilla luciferase reporter gene, that is constitutively expressed under the control of an internal ribosome entry site (IRES) and is not regulated by steroid hormones. The corresponding SHR (wildtype or mutant/variant) is also expressed from the same construct. Using this improved reporter system, we revealed a large spectrum of transactivation activities within a set of previously identified mutations and variations of the androgen receptor (AR), the estrogen receptor $\alpha$ $(E R \alpha)$ and the glucocorticoid receptor (GR). This novel reporter system enables functional analysis of SHR mutants and variants in physiological and pathological settings, offering valuable preclinical, or diagnostic information for the understanding and treatment of associated diseases.

Keywords: steroid hormone receptors (SHRs), mutations, splicing variations, dual-luciferase reporter assay, transactivation activity 


\section{INTRODUCTION}

Many SHR variants have been identified in both common and rare diseases (1-3). All SHRs share a similar domain organization, including a C-terminal ligand-binding domain (LBD), a hinge region, a DNA-binding domain (DBD), and a N-terminal domain (NTD). SHR variants may have cis- or trans-effects on multiple genes. Naturally existing GR variants (truncated or mutated receptors) for example, are one of the main causes of corticosteroid resistance (1), and mutations in AR could cause androgen insensitivity syndrome (AIS), spinal and bulbar muscular atrophy, and prostate cancer (2). Alterations in SHRs are also a common underlying mechanism for drug resistance in cancer therapy (4). For instance, splicing variations and mutations in $\mathrm{AR}$ are associated with the progression of castration-resistant prostate cancer (CRPC) (5). Mutations in $\mathrm{ER} \alpha$ have also been identified in hormone therapy resistant breast cancer treated with selective $\mathrm{ER} \alpha$ modulators such as tamoxifen and raloxifene (3). Although many disease-associated SHR splicing variants and mutants have been identified, very few of them have been functionally analyzed, in part, due to the lack of a general platform that can quantitatively evaluate and compare the transcriptional activities of SHR variants and mutants.

Luciferase reporter assays have been used for studying many cellular processes including intracellular signaling, gene expression, receptor activity, transcription factors, mRNA processing, and protein folding. Dual luciferase reporter systems have been used in the past to assay SHR activity in gene regulation with improved accuracy by using one luciferase as an internal control. These systems usually involve co-transfection of three expression vectors (including the SHR expression vector, the experimental reporter gene vector, and the internal control reporter gene vector) into a cell line, which could introduce additional variables and thus impact assay accuracy. In this study we engineered multiple single-vectored, dual-luciferase reporters that can rapidly and accurately measure the activity of individual SHRs in cells. These reporters contain a constitutively expressed Renilla luciferase reporter gene under the control of an internal ribosome entry site (IRES), an SHR-expressing cassette, and a firefly luciferase reporter gene driven by a promoter that is regulated by the corresponding SHR. Using these improved reporter systems, we undertook a comprehensive survey of a large number of $\mathrm{AR}, \mathrm{ER} \alpha$ and GR variants that were previously identified in clinical or preclinical studies. Our results reveal distinct transcriptional activities of these variants, providing insights into their roles in the pathogenesis of associated diseases.

\section{MATERIALS AND METHODS}

\section{Cell Lines and Culture Conditions}

The Huh-7 and COS-7 cells were obtained from Peking Union Medical College (PUMC, Beijing, China). PC3 cells were cultured in RPMI-1640 medium (Gibco) supplemented with 10\% FBS (Gibco) in a humidified atmosphere with $5 \% \mathrm{CO}_{2}$. Huh-7, COS-7, Hela, HEK293T, and HepG2 cells were cultured in phenol DMEM $(\mathrm{H})$ medium (Thermo Fisher Scientific, Waltham,
MA USA) supplemented with $10 \% \mathrm{FBS}$ (Gibco) at $37^{\circ} \mathrm{C}$ in a humidified atmosphere with $5 \% \mathrm{CO}_{2}$.

\section{Cloning of Constructs}

PSA61-Luc(obtained from Jan Trapman and Hetty van der Korput, Erasmus MC, Netherlands), pcDNA3.1(+)-AR and pSG5-hER $\alpha$ were kindly provided by Jörg Klug, JLU Giessen, Germany. $4 \times$ ARE-Luc and $2 \times$ GRE-Luc plasmids were kindly provided by Prof. Michael Carey at UCLA and Iain J. McEwan at University of Aberdeen, respectively. The ARE-I-II-III-Luc vector was generated by replacing the PSA61 region in PSA61Luc (between the BamHI and EcoRI sites) with an ARE-I-II-III fragment (amplified through overlapping PCR).

The pcDNA3.1(-)-4×ARE-Fluc-AR-Rluc was generated through the following steps: (a) the CMV promoter in pcDNA3.1(-) vector was replaced with the $4 \times$ ARE and minimal promoter, amplified from the $4 \times \mathrm{ARE}-L u c$ plasmid; (b) the firefly luciferase gene was inserted into the pcDNA3.1(-)-4xARE vector downstream of the minimal promoter; (c) the neomycin gene in the pcDNA3.1(-)-4×ARE-Fluc was replaced with IRES and the Renilla luciferase reporter gene; (d) the full length wild type AR fragment was then inserted upstream of the IRES sequence in pcDNA3.1(-)-4×ARE-Fluc-Rluc between the XhoI and $\mathrm{XbaI}$ sites.

To generate pcDNA3.1-4×ARE-Fluc-AR-Vs-Rluc constructs, various $A R$ variant sequences (AR-Vs) were amplified by PCR from pcDNA3.1(+)-AR based on previous studies (6-10), which were then used to replace the AR region (between the XhoI and XbaI sites) in pcDNA3.1-4 $\times$ ARE-Fluc-AR-Rluc.

To generate pcDNA3.1-4×ERE-Fluc-ER $\alpha$-Vs-Rluc plasmids, a $4 \mathrm{xERE}$ promoter sequence containing four copies of ERE was synthesized by Qingke Biotech (Beijing, China) a. ER $\alpha$ wildtype cDNA was amplified from pSG-hER $\alpha$ and used to replace the AR cDNA in pcDNA3.1(-)-4 $\times$ ARE-Fluc-AR-Rluc. ER $\alpha$ variant and mutant sequences were generated by overlapping PCR and used to replace $\mathrm{ER} \alpha$-wt cDNA in the vector to generate pcDNA3.1$4 \times$ ERE-Fluc-ER $\alpha$-Vs-Rluc expression constructs.

To generate pcDNA3.1(-)-4×GRE-Fluc-GR-Vs-Rluc, the $4 \times$ GRE promoter sequence was amplified from the $2 \times$ GRE-Luc vector by overlapping PCR, and the wildtype GR CDNA was amplified from cDNA isolated from HeLa cell, as described (11). $4 \times$ GRE and wildtype GRcDNA were then used to replace $4 \times \mathrm{ARE}$ and the AR-wt cDNA in pcDNA3.1(-)-4×ARE-FlucAR-Rluc. GR-wt cDNA was then replaced with different GR variants cDNA generated by overlapping PCR.

Sequences of all the primers used to create AR-wt, ER $\alpha$-wt, and GR-wt cDNA, as well as their corresponding variants and mutations, are described in Tables S1-S6. The sequences of ARE, GRE and ERE are provided in the Table S7.

\section{Luciferase Reporter Assays}

HEK293T cells were seeded in 6-well plates and cultured in complete medium containing 10\% charcoal-stripped fetal bovine serum (Sijiqing, ZhejiangTianhang, Biotechnology, China) for $24 \mathrm{~h}$. Subsequently, they were transfected with different constructs using the Lipofectamine 3000 transfection reagent (ThermoFischer Scientific Inc., Waltham, MA, USA) according 
to the manufacturer's protocol. Six hours after transfection, the medium was replaced with fresh charcoal-stripped medium containing either corresponding hormones [R1881 (Yuanye, Shanghai, China), diethylstilbestrol (Aladdin, Shanghai, China), dexamethasone (Sigma-Aldrich, Sweden)], or DMSO solvent (Sangon, Shanghai, China). After $48 \mathrm{~h}$ of incubation, cells were then washed, lysed, and harvested. Dual-Luciferase Reporter Assay (Promega, Madison, WI) was then performed in duplicates to measure the activities of firefly luciferase and Renilla luciferase. Transfection efficiency was normalized by Renilla luminescence signals. The results are presented as the mean \pm SD of triplicate samples.

\section{Statistical Analysis}

All reported values represent the average of triplicates. Statistical analysis of differences between samples was performed using two-tailed student's $t$-test and $P<0.05$ is considered significant. Data are presented as mean $\pm \mathrm{SD}$. Analysis was conducted using Prism v6.0c (GraphPad Software).

\section{RESULTS}

\section{Selection for Appropriate Transfected Cell Lines, Effective Promoters, and Optimal Stimulus Concentration}

In general, activation of receptors requires not only ligands binding but also recruitment of various coactivators to the transcriptional complex. Thus, an appropriate cellular context and a sensitive and effective promoter are important factors for consideration for assessing AR transcriptional activity. After surveying androgen regulation of PSA61-Luc in six AR-negative cell lines, we found the promoter displayed the highest fold stimulation activity (16.6-fold change) in HEK293T compared to other cell lines (Figure S1). Whereas ARE-I-II-III and $4 \times$ ARE reporters displayed 11.6 - and 55-fold change stimulation in HEK293T (Figure S2). Therefore, we chose HEK293T and $4 \times$ ARE-Luc to examine the transcriptional activity of AR-wt.
In order to assess the effects of AR alterations in low androgen concentrations in castration environments, we constructed pcDNA3.1-4×ARE-Fluc-AR-wt-Rluc reporter (Figure 1A) and transfected it into HEK293T. As shown in the Figure S3A, 10nM R1881, which confers comparable stimulation effects with $100 \mathrm{nM}$ R1881 but higher stimulatory effects than 0.1 or $1 \mathrm{nM} \mathrm{R} 1881$, is chosen for comparing the transcriptional activity of AR-wt and its mutants or variants. Similarly, we constructed pcDNA3.1$4 \times$ ERE-Fluc-ER $\alpha$-wt-Rluc and pcDNA3.1-4 $\times$ GRE-Fluc-GR-wtRluc reporters (Figures 1B,C) and chose 1.0nM diethylstilbestrol (DES) and 10nM dexamethasone (DEX) physiologically-relevant concentration as the ligand concentration to evaluate the transcription activity of $\mathrm{ER} \alpha$ variants and GR variants, respectively (Figures S3B,C).

\section{Effects of Prostate Cancer-Associated AR Mutations and Splicing Variations on Transcription}

After surveying six different cell lines and three promoters displaying different efficiency of activation, we chose HEK293T and $4 \times$ ARE-Luc to compare the transcriptional activity of AR-wt and its mutants or variants (Figures S1, S2A,B). In order to assess the effects of AR alterations in low androgen concentrations in castration environments, we chose the $10 \mathrm{nM}$ R1881 physiological concentration (Figure S3A).

As shown in Figure 2, nine variants (AR-V4, AR-V5, ARV6, AR-V7, AR-V8, AR-V9, AR-V11, AR-V12, and ARQ640X) exhibited constitutive transcriptional activity in the absence of R1881. Consistent with the previous reports $(6,7), A R-V 7$ and AR-V12 (also known as AR v567es), both of which are the most frequently expressed variants in clinical specimens, displayed the highest luciferase activity in the absence of R1881 (which were 91 and 81 more active than AR-wt, respectively) (Table 1). Q640X, a truncation mutant with a point mutation that leads to a premature stop codon at position 640 of the AR, strongly activated $4 \times \mathrm{ARE}$ promoter (71 times of the basal activity of
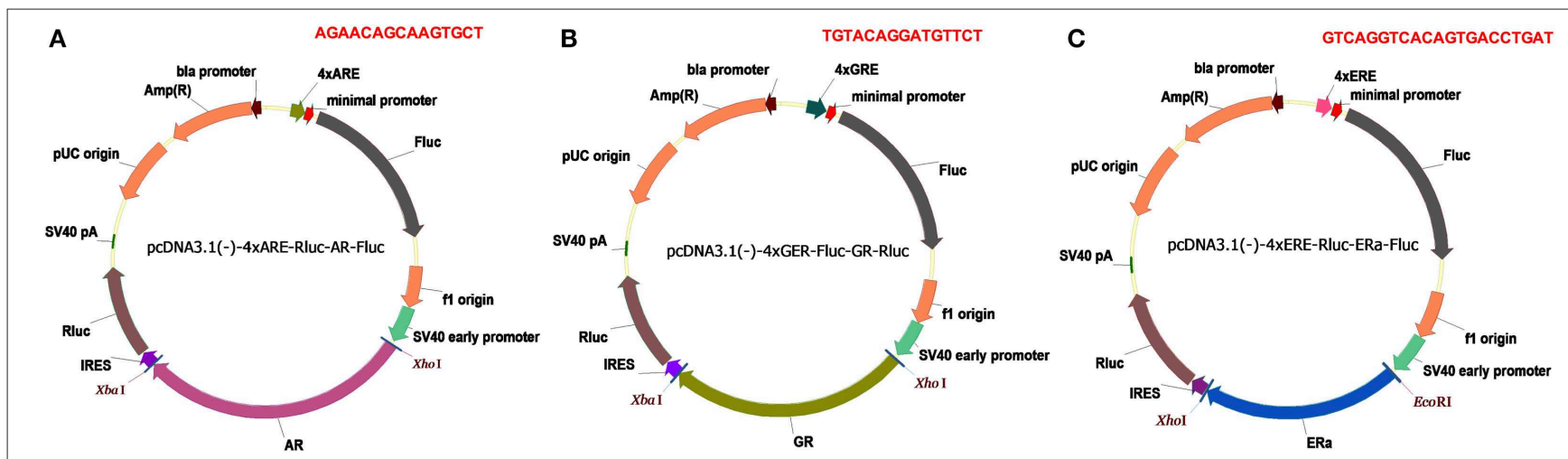

FIGURE 1 | Dual luciferase reporters for SHRs. (A) pcDNA3.1(-)-4xARE-Fluc-AR-Rluc reporter. (B) pcDNA3.1-4xGRE-Fluc-GR-Rluc reporter. (C) pcDNA3.1-4xERE-Fluc-ERa-Rluc reporter. Amp(R), ampicillin resistance gene; Fluc, firefly luciferase gene; Rluc, Renilla luciferase gene; SV40 early promoter, simian vacuolating virus 40 early promoter; IRES, internal ribosome entry site; $4 \times A R E$, four copies of androgen responsive elements; $4 \times E R E$, four copies of estrogen responsive elements; $4 \times \mathrm{GRE}$, four copies of glucocorticoid responsive element; the responsive element sequences are highlighted in red. 


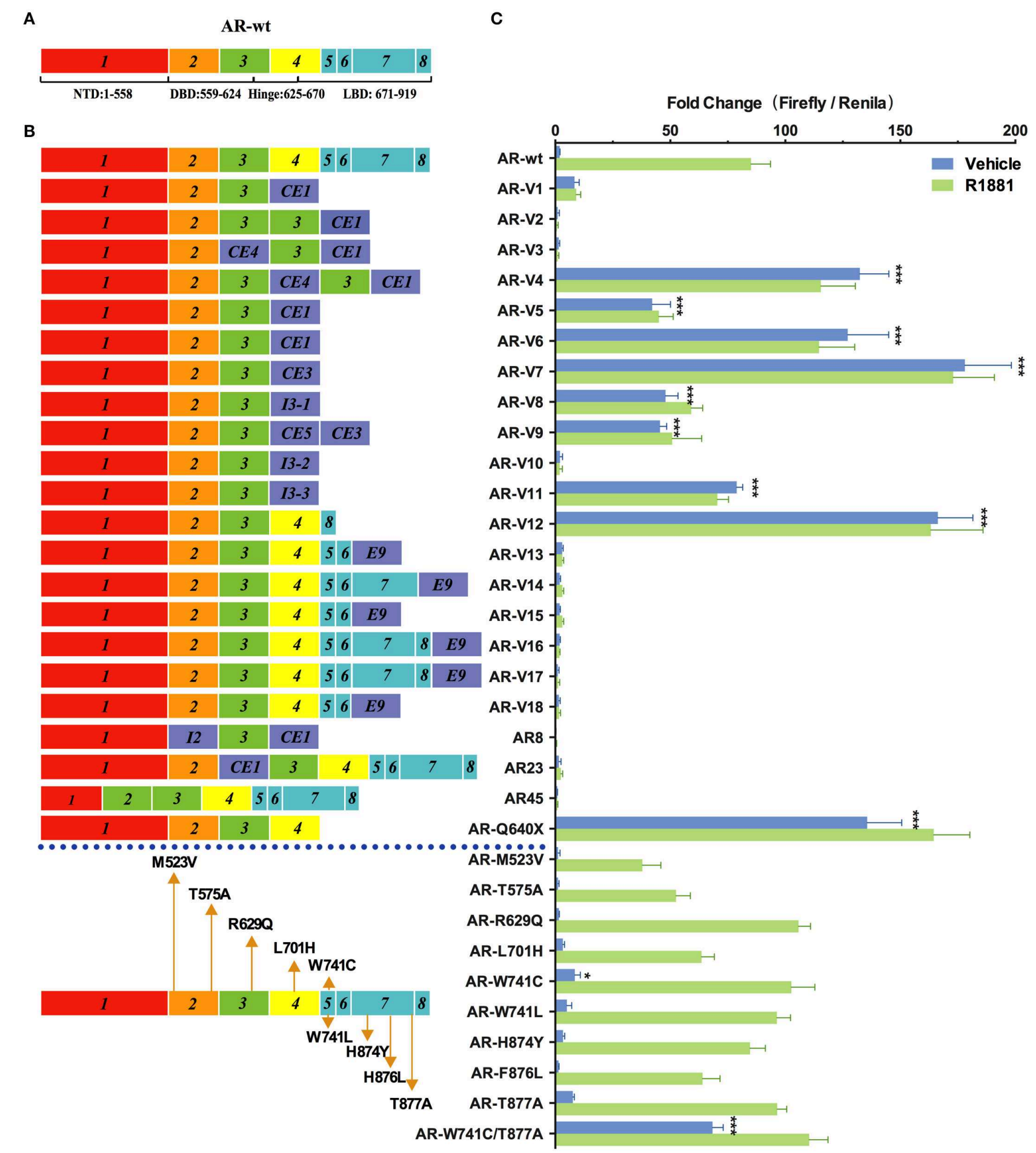

FIGURE 2 | Effects of AR mutations and splicing variations on transcription. (A) Domain structure of AR-wt. (B) AR mutants and variants tested. (C) Transcriptional activity of transfected AR mutants in HEK293T cells treated with $10 \mathrm{nM}$ of R1881 or vehicle for $48 \mathrm{~h}$. Results represent the mean \pm SD of three biological replicates. ${ }^{\star} P<0.05 ;{ }^{\star \star \star} P<0.001$. AR, androgen receptor; AR-FL, full-length androgen receptor; AR-Vs, androgen receptor variants; AF, activation function; CE, cryptic exon; CRPC, castration-resistant prostate cancer; DBD, DNA-binding domain; I, intron; LBD, ligand-binding domain; NTD, N-terminal domain; NLS: nuclear localization sequence. 
TABLE 1 | Selected resistance mechanisms by type of androgen receptor (AR) or estrogen receptor modification.

\begin{tabular}{|c|c|c|c|c|}
\hline Modification & Clinical relevance & Biological relevance & Mechanism & References \\
\hline \multicolumn{5}{|l|}{ AR variants } \\
\hline$A R-V 7$ & $\begin{array}{l}\text { Enriched in CRPC and metastasis, } \\
\text { high risk of recurrence, decreased } \\
\text { PFS and OS of CRPC patients }\end{array}$ & $\begin{array}{l}\text { Resistant to ADT, enzalutamide and } \\
\text { abiraterone }\end{array}$ & $\begin{array}{l}\text { Constitutive } \\
\text { activation }\end{array}$ & (6) \\
\hline AR-V9 & $\begin{array}{l}\text { Enriched in CRPC and metastasis } \\
\text { decreased PFS of CRPC patients }\end{array}$ & $\begin{array}{l}\text { Resistant to ADT, enzalutamide and } \\
\text { abiraterone }\end{array}$ & $\begin{array}{l}\text { Conditional } \\
\text { activation }\end{array}$ & $(12)$ \\
\hline AR-V12 (ARv567es) & $\begin{array}{l}\text { Enriched in CRPC and metastasis } \\
\text { decreased PFS of CRPC patients }\end{array}$ & $\begin{array}{l}\text { Resistant to ADT, drives invasive } \\
\text { adenocarcinoma in vivo }\end{array}$ & $\begin{array}{l}\text { Constitutive } \\
\text { activation }\end{array}$ & (7) \\
\hline \multicolumn{5}{|l|}{ AR mutations } \\
\hline L701H & Existed in metastatic CRPC & Activated by glucocorticoids & Receptor promiscuity & $(13)$ \\
\hline W741C & Existed in metastatic CRPC & Activated by bicalutamide, flutamide & Antagonist-to-agonist switch & (5) \\
\hline W741L & Existed in metastatic CRPC & Resistant to Abiraterone & Antagonist-to-agonist switch & $(14)$ \\
\hline H874Y & Existed in metastatic CRPC & $\begin{array}{l}\text { Activated by estrogen, progesterone, } \\
\text { glucocorticoids, adrenal androgens, } \\
\text { bicalutamide, flutamide, enzalutamide } \\
\text { and apalutamide }\end{array}$ & $\begin{array}{l}\text { Antagonist-to-agonist switch, Receptor } \\
\text { promiscuity }\end{array}$ & $(15)$ \\
\hline F876L & Existed in metastatic CRPC & $\begin{array}{l}\text { Activated by flutamide, apalutamide and } \\
\text { enzalutamide }\end{array}$ & Antagonist-to-agonist switch & $(16)$ \\
\hline T877A & Existed in metastatic CRPC & $\begin{array}{l}\text { Activated by progesterone, estrogen, } \\
\text { flutamide, bicalutamide, enzalutamide } \\
\text { and apalutamide }\end{array}$ & $\begin{array}{l}\text { Antagonist-to-agonist switch, Receptor } \\
\text { promiscuity }\end{array}$ & $(5,17)$ \\
\hline \multicolumn{5}{|l|}{ ER mutations } \\
\hline Y537S & $\begin{array}{l}\text { Existed in metastatic ER+ breast } \\
\text { cancer, decreased PFS and OS }\end{array}$ & $\begin{array}{l}\text { Resistance to the beneficial effects of } \\
\text { the SERM, SERD, and Als. }\end{array}$ & $\begin{array}{l}\text { Constitutive } \\
\text { activation }\end{array}$ & $(18-20)$ \\
\hline D538G & $\begin{array}{l}\text { Existed in metastatic ER+ breast } \\
\text { cancer, decreased PFS and OS }\end{array}$ & $\begin{array}{l}\text { Resistance to the beneficial effects of } \\
\text { the SERM, SERD, and Als. }\end{array}$ & $\begin{array}{l}\text { Constitutive } \\
\text { activation }\end{array}$ & $(18-20)$ \\
\hline \multicolumn{5}{|l|}{ GR mutations } \\
\hline D641V & $\begin{array}{l}\text { Existed in generalized glucocorticoid } \\
\text { resistance }\end{array}$ & Reduced sensitivity to glucocorticoids & $\begin{array}{l}\text { Decreased bind ability to GRE; abnormal } \\
\text { interaction with GRIP1; dominant negative } \\
\text { effect on GR-wt }\end{array}$ & $(11)$ \\
\hline $\mathrm{R} 477 \mathrm{H}$ & $\begin{array}{l}\text { Existed in Hirsutism and generalized } \\
\text { glucocorticoid resistance }\end{array}$ & Reduced sensitivity to glucocorticoids & Decreased affinity to GREs & $(21)$ \\
\hline V729l & $\begin{array}{l}\text { Existed in generalized glucocorticoid } \\
\text { resistance with homosexual } \\
\text { precocious puberty }\end{array}$ & Reduced sensitivity to glucocorticoids & $\begin{array}{l}\text { Decreased interaction with NCoA, affinity } \\
\text { to ligand and nuclear translocation; hamper } \\
\text { the formation of homodimer }\end{array}$ & $(22)$ \\
\hline
\end{tabular}

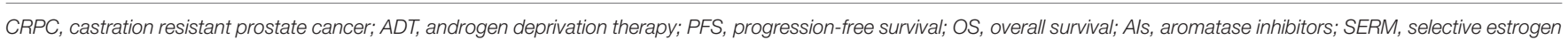

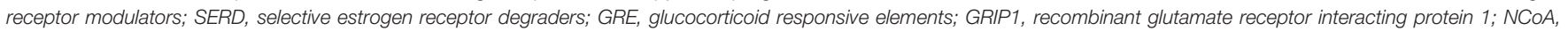
nuclear receptor coactivators.

AR-wt), in agreement with a previous observation (23). ARV7 and ARV567es exhibited similar transcriptional activity to Q640X (Figure 2). Less-studied AR-Vs such as AR-V4, ARV5 and AR-V6 were found in CRPC metastases, with lower expression levels than AR-V7 or AR-V9(13). However, lowabundance AR-Vs including AR-V4, AR-V5, AR-V6, AR-V8 and AR-V11 displayed remarkable constitutive activity in stimulating transcription $(69 \times, 22 \times, 66 \times, 25 \times, 41 \times$, and $25 \times$ basal activity of AR-wt, respectively). AR-V9 displayed modest transcriptional activity $(24 \times$ basal activity of AR-wt) in a ligand-independent manner, in line with previous observations (12). Because some variants such as AR-V7 and AR-V9 are frequently co-expressed in CRPC metastases $(12,13)$, and because AR-Vs can form heterodimers/homodimers (24), it is possible that their combined contribution to prostate cancer progression might be greater than their individual effects.
Among the 22 AR variants examined, 13 displayed a complete loss of function in the presence or in the absence of R1881. Some of them, including AR-V1, AR-V2, AR23, AR45, and AR8, have been characterized before $(6,9,25,26)$. They were previously suggested to function through a non-genomic mechanism or cytoplasmic action $(9,25)$. However, other variants (e.g., ARV10, AR-V13, AR-V14, AR-V15, AR-V16, AR-V17 and AR-V18) were identified more recently in certain cell lines or tissues and have not been functionally analyzed $(8,27)$. AR-V3, which was exclusively found in CRPC (13), was previously suggested to display constitutive transcriptional activity that is even higher than the reported activity of AR-V7 in DU-145 cells (28). However, in our analysis, this variant was completely inactive.

AR mutations are rare in the early stages of untreated PC in patients, but occur much more frequently in castrationresistant prostate cancer (CRPC) (29). Gain-of-function 
mutations in AR allow prostatic epithelial cells to grow in an androgen-independent manner. In our study, the double mutant W741C/T877A exhibited higher transcription activity $(36 \times$ basal AR-wt levels) than W741C or T877A single mutant in the absence of hormone, and this activity was further enhanced by R1881 (Figure 2). This indicates that W741C and T877A mutations may cooperate to confer new properties on AR. L701H, W741L/C, H874Y, and F876L, all of which were detected in CRPC patients (Table 1), displayed similar transcriptional activity to AR-wt. The R629Q mutation in the hinge region important for DNA binding and nuclear translocation of AR, caused a mild increase of transcriptional activity in the presence of R1881 (1.3× basal AR-wt levels) (Figure 2). M523V and T575A, both of which were detected in metastatic PCa and patients receiving combined androgen blockade, displayed a modest decease of transcriptional activity (44 and 62\% of AR-wt levels) in the presence of R1881 (Figure 2).

\section{Effects of Disease-Associated ER $\alpha$ Mutations and Splicing Variations on Transcription}

Since discovered in early 1990s, many naturally occurring splice variants of ER $\alpha$ with different coding sequences have been identified in cell lines and clinical samples $(30,31)$. To examine the transcriptional activity of these ER $\alpha$ variants, we constructed a series of pcDNA3.1-4 $\times$ ERE-Fluc-ER $\alpha$-Rluc reporters expressing WT and ER $\alpha$ variants (Figure 1B). We chose $1.0 \mathrm{nM}$ diethylstilbestrol (DES), which confers maximal stimulatory effects on the $4 \times$ ERE promoter (Figure S3B), as the ligand concentration to evaluate the transcription activity of $\mathrm{ER} \alpha$ variants. Among the nine $\mathrm{ER} \alpha$ splice variants examined, only ER $\alpha$-V5 (which lacks the exon 5) exhibited modest transcriptional activity $(25 \times$ basal $\mathrm{ER} \alpha$-wt levels) in the absence of DES (which is consistent with previous reports) (Figure 3) (31, 32). The TADDI variant, which contains a $31 \mathrm{bp}$ deletion between exons 3 and 4 and a 13 bp insertion in this splice site and which is increased in postmenopausal women in the hippocampus, is 1.42 times more active than $\mathrm{ER} \alpha$-wt in stimulating transcription in the presence of DES (Figure 3). The ER $\alpha-V 6, E R \alpha 36$, and ER $\alpha 46$ variants displayed a similar transcriptional activity $(1.4 \times$ basal ER $\alpha$-wt levels) in the presence of DES (Figure 3). The other four variants $(\mathrm{ER} \alpha-\mathrm{V} 2, \mathrm{ER} \alpha-\mathrm{V} 3, \mathrm{ER} \alpha-\mathrm{V} 4$, and $\mathrm{ER} \alpha-\mathrm{V} 7)$ apparently have no transcriptional activity (Figure 3), consistent with previous reports $(30,33)$.

In addition to splicing variants, we also examined the transcriptional activity of $\mathrm{ER} \alpha$ mutants which have been identified in 10 to $54.5 \%$ metastatic, $\mathrm{ER} \alpha$-positive breast cancers $(18,19,34)$. Among the 20 cancer-relevant mutants examined, S463P/D538G showed the highest levels of transcriptional activity in the absence of DES (133 $\times$ basal ER $\alpha$-wt levels), which is followed by Y537N/D538G and Y537S/D538G (108× and $95 \times$ basal $\mathrm{ER} \alpha$-wt levels), and single mutant Y537S, D538G, and $\mathrm{Y} 537 \mathrm{~N}(79 \times, 24 \times$, and $5 \times$ basal ER $\alpha$-wt levels). The above mutants, except for D538G and Y537N, induced a similar transcriptional activity in the presence of $1 \mathrm{nM}$ of DES compared with themselves in the absence of hormone. In the presence of DES, D538G, and Y537N were both highly active and induced transcription to a similar level to that of Y537S/D538G. The ER $\alpha$ mutations described above occur frequently in various breast cancer samples, and only some of them have been characterized $(18,19)$ (Table 1). Patients with certain ER $\alpha$ mutations have a shorter progression-free survival (PFS) and overall survival (OS) following endocrine treatment, compared to patients with $\mathrm{ER} \alpha-$ wt $(20,35,36)$. In contrast to our results, Spoerke et al. did not find differential PFS in patients with $\mathrm{ER} \alpha$ mutations compared with wild-type patients (37). However, that study included some other mutations including E380Q, S463P, Y536P, and Y537C, whose transcriptional ability tested in our system were similar to that of ER $\alpha$-wt or even less sensitive than that of ER $\alpha$ wt in the presence of DES. Thus, we hypothesize that not all mutations are related with the clinical outcomes, but mutations showing constitutive ability should be carefully focused on. Some mutations identified in advanced ER + breast cancer exhibited similar (L469V, L536H, and L536Q) or a modest decease (P535H and L536R) of luciferase activity relative to $\mathrm{ER} \alpha$-wt in our study. Notably, A350F completely lost the transactivation activity in our study. These results suggest that the contribution of the transcriptional activity of $\mathrm{ER} \alpha$ mutations to tumorigenesis is likely to be very complex.

Previous structural studies indicated that Y537S and D538G mutations cause increased interaction of $\mathrm{ER} \alpha$ with its coactivators such as SRC-1, due to the shift of helix 12 to a conformation similar to that of estrogen-bound ER $\alpha$-wt (38). Other mutations at the same site 537 and 538, including Y537A, Y537C, Y537D, Y537E, Y537K, and D538N, did not induce transactivation in the absence of DES, indicating the nature of the mutations is critical for the changes in ER $\alpha$ activity. Y537E and D538N exhibited 1.65- and 1.45-fold increase in transactivation activity, respectively, compared with ER $\alpha$-wt, but only in the presence of DES.

\section{Effects of Disease-Associated GR Mutations and Splicing Variations on Transcription}

GR is another important member of nuclear receptor family that also contains multiple variants and is frequently mutated in cancer and other diseases. To investigate their transcriptional activity, we generated pcDNA3.1(-)-4×GREFluc-GR-Rluc reporters expressing a serial of GR mutants and splice variants (Figure 4). The $10 \mathrm{nM}$ DEX physiologicallyrelevant concentration was chosen for the comparisons of the transcriptional activity (Figure S3C).

Increased expression of GR $\beta$ (which does not contain helix 12 of LBD but has a different amino acid sequence in helix 11 compared to GR-wt) was observed in hormoneinsensitive autoimmune diseases (39), blood system diseases (40), cancer (41), etc. As shown in Figure 4 transfected GR $\beta$ exhibited little transactivation activity in the presence or absence of glucocorticoids, consistent with previous studies (39, 40). When GR-wt and GR $\beta$ were co-transfected in a 1:1 ratio, the transactivation activity of GR-wt decreased dramatically. These observations raise the possibility that abnormally increased GR $\beta$ may decrease hormone sensitivity by inhibiting GR-wt. 


\section{A}

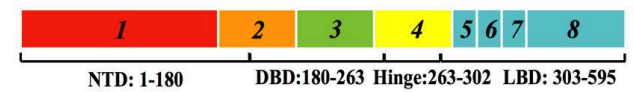

B

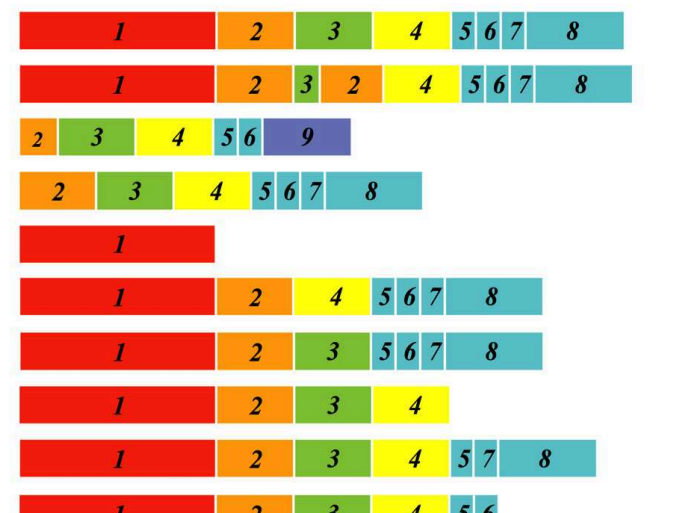

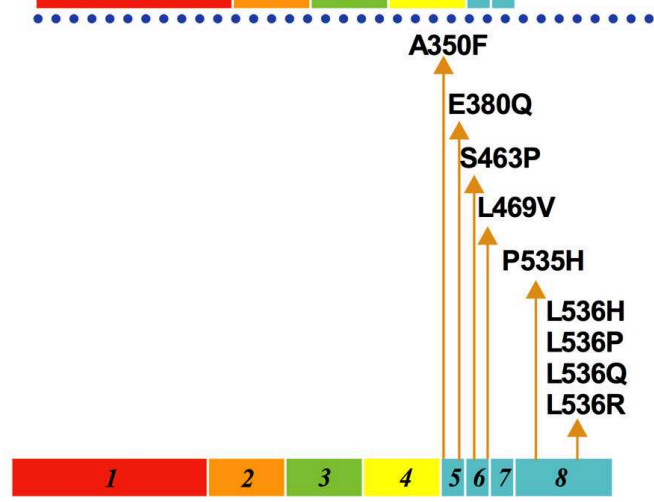

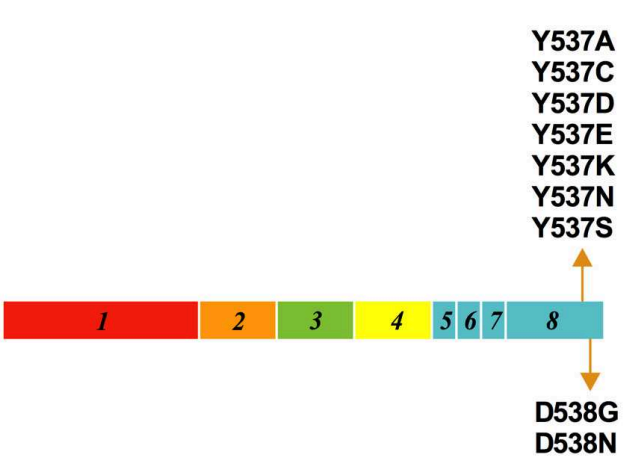

C

Fold Change (Firefly / Renila)

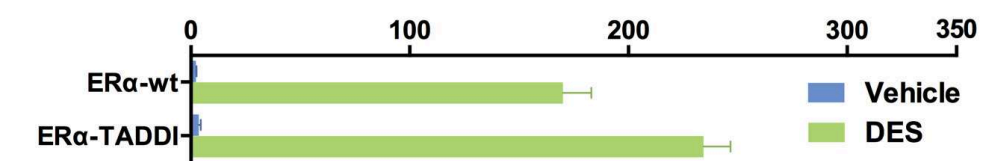

ER $\alpha$-TADDI- $\quad$ Dehic

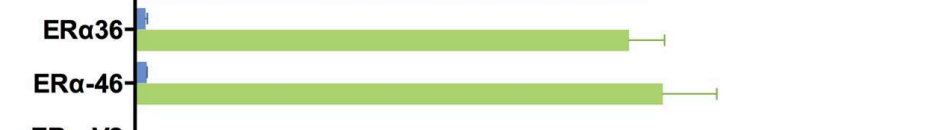

$E R \alpha-V 2-$

ERa-V3-

ERa-V4-

ERa-V5-

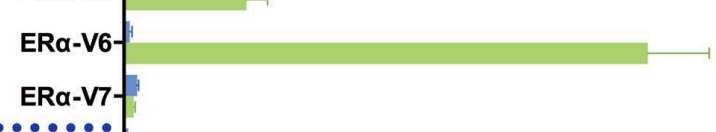

$E R \alpha-V 7-$

ERa-A350F

ER $\alpha-E 380 Q-$

\section{ERa-S463P-}

ERa-L469V

ERa-P535H-

ERa-L536H-

ERa-L536P-

ER $\alpha-L 536 Q-$

ERo-L536R-

ERa-Y537A-

ER $\alpha-Y 537 A-$
ER $\alpha-Y 537 C-$

ERa-Y537D-

ERa-Y537E-

ERa-Y537K-

ERa-Y537N-

$-+\frac{*}{*}$

ERa-Y537S-

ERa-D538G

$E R \alpha-D 538 N$

ERa-S463P/D538G-

ER $\alpha-Y 537 S / D 538 G$

ERa-Y537N/D538G-

FIGURE 3 | Effects of ER mutations and splicing variations on transcription. (A) Domain structure of ER $\alpha$-wt. (B) Location of tested mutations in ER $\alpha$. (C) Transcriptional activity of transfected ER $\alpha$ mutants in HEK293T cells treated with $1 \mathrm{nM}$ of diethylstilbestrol (DES), or vehicle for $48 \mathrm{~h}$. Results represent the mean \pm SD of three biological replicates. ${ }^{\text {tw* }} P<0.001$. ER $\alpha$-wt, wide-type estrogen receptor- $\alpha$; ER $\alpha$-Vs, estrogen receptor variants; DBD, DNA-binding domain; LBD, ligand-binding domain; NTD, N-terminal domain.

The mRNA of GR-P variant accounts for $10-20 \%$ of total GR RNA in normal cells, which is much higher than GR- $\beta$. Certain blood cancer (e.g., multiple myeloma) and solid tumors (e.g., breast cancer) have increased GR-P, up to $50 \%$ of total GRmRNA. However, it exhibited virtually no transactivation activity in our assay. 
A

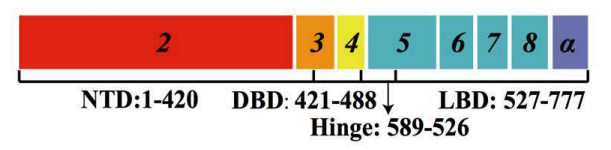

B

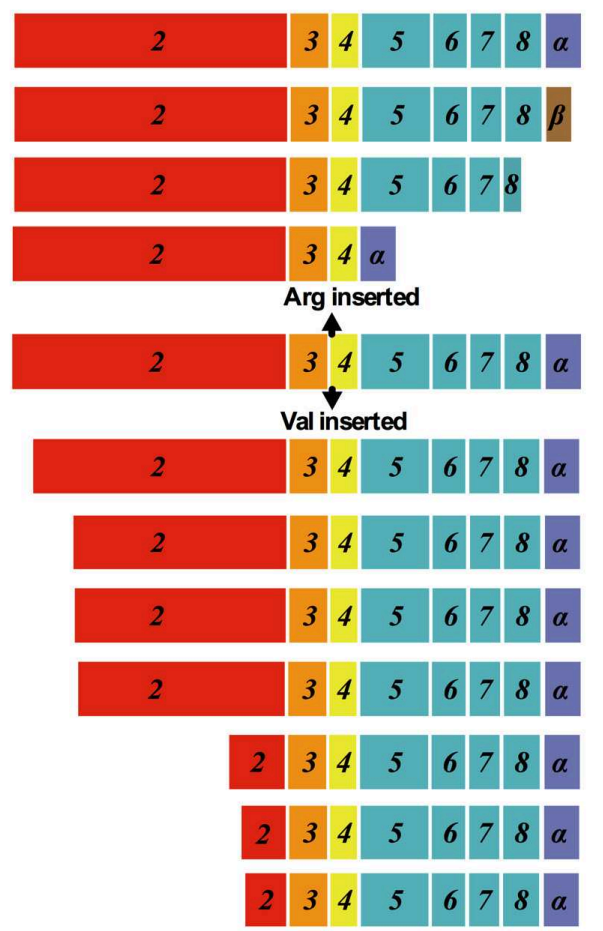

C

Fold Change (Firefly / Renila)

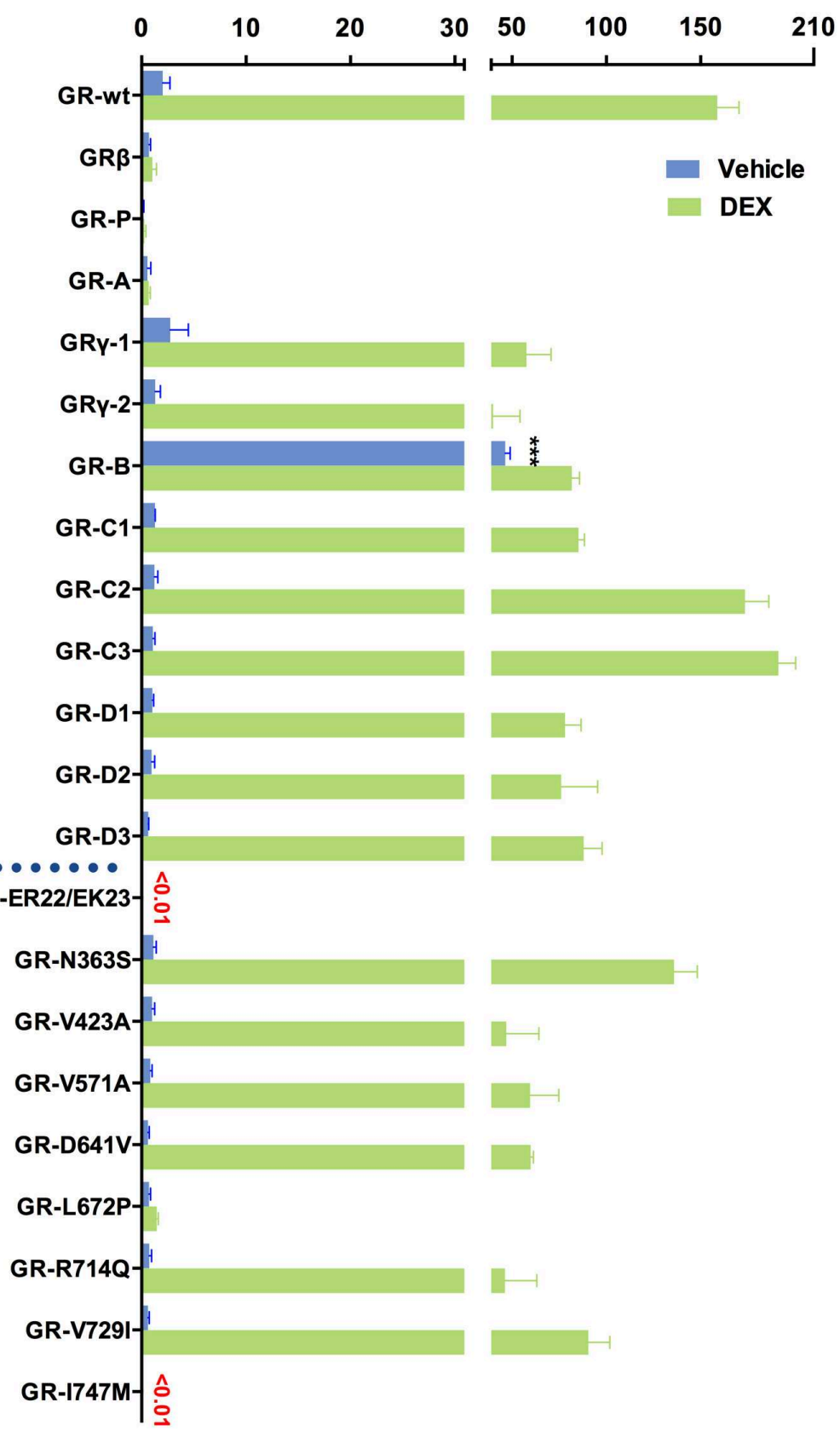

FIGURE 4 | Effects of GR mutations and splicing variations on transcription. (A) Domain structure of GR-wt. (B) Location of tested mutations in GR. (C) Transcriptional activity of transfected GR mutants in HEK293T cells treated with $10 \mathrm{nM}$ of dexamethasone(DEX) or vehicle for $48 \mathrm{~h}$. Results represent the mean $\pm \mathrm{SD}$ of three biological replicates. " $P<0.001$. GR-wt, wide-type glucocorticoid receptor; GR-Vs, glucocorticoid receptor variants; DBD, DNA-binding domain; LBD, ligand-binding domain; NTD, N-terminal domain.

GR-A, which lost exons 5-7 during alternative splicing, lacks trans-acting regions and nuclear localization regions. Consistently, the observed transactivation activity of GR-A was minimal. The increase of GR-A expression may contribute to glucocorticoid insensitivity.
GR- $\gamma$, which is associated with hormone insensitivity in leukemia and non-small cell lung cancer (42), contains an arginine insertion between exons 3 and 4 . The transactivation ability of GR- $\gamma$ was significantly lower than that of GRwt, although it was higher than GR-A, GR-P, and GR $\beta$. 
Increased expression of GR- $\gamma$ may also contribute to glucocorticoid insensitivity.

In addition to splicing variants, we also examined the transcriptional activity of multiple translation variants of GR. Expression of these translational variants is tissue- and cellspecific and might be one of the mechanisms underlying their different varying sensitivity. These translational variants might also contribute to glucocorticoid-related side effects. For instance, higher levels of translational variants C2 and C3 in some patients may result in higher glucocorticoids sensitivity and more frequent side effects such as glucocorticoid-induced osteoporosis. GR-C1, GR-D1, GR-D2, and GR-D3 exhibited clear loss of function compared with GR-wt in the presence of DEX. Both GRC2 and GR-C3 had slightly higher transcriptional transactivation than GR-wt when treated with $10 \mathrm{nM}$ DEX, consistent with a previous report (43). The transactivation activity of GR$B$ increased by several times compared with GR-wt in the absence of hormones (Figure 4), suggesting that GR-B might be associated with abnormally high GR activity under normal physiological conditions.

Primary glucocorticoid resistance due to mutations in the GR gene was found in 23 cases, most of which were single nucleotide mutations $(21,44)$, insertions (45), and deletions (46). Mutations occurred mostly in the ligand binding region, and have a significant effect on the function of GR. LP72P was first identified in a male patient who had no symptoms except bilateral adrenal hyperplasia, but function experiments showed that the mutant L672P had no transactivation ability (21). We also obtained a similar result (Figure 4). The I747M mutation was reported a family with primary glucocorticoid resistance as well as a series of other symptoms including irregular menstrual cycles, hyperandrogenism, cystic acne, and hairiness (47). Our result show that I747M also has extremely low transactivation ability.

We also explored the relationship between two common SNPs and glucocorticoid sensitivity. N363S had been reported to be associated with increased glucocorticoid sensitivity, decreased bone density (48), and frequent hormone-related side effects (49). In our study, however, the transactivation activity of N363S was actually slightly lower than that of the wild type, although the difference was not statistically significant (Figure 4). Another common SNP, ER22/23EK, resulted in almost complete loss of GR activity (Figure 4), which might be associated with decreased sensitivity of glucocorticoids.

\section{DISCUSSION}

The frequent alterations of $\mathrm{AR}, \mathrm{ER} \alpha$, and $\mathrm{GR}$ genes are clinically important due to their specific functional differences (Table 1). The estimated overall benefit of the molecularlyinformed treatment decision was significantly higher over the uninformed (50). In this study, we developed rapid and accurate reporter systems for profiling SHR alterations, which may help individualized treatment decision-making. Our reporter systems overcome the limitations of previously developed dual luciferase reporter assays where several different vectors need to be co-transfected into cells. The inclusion of the Renilla reporter gene downstream SHR mRNA under the control of IRES for expression normalization ensures that the firefly luciferase reporter activity accurately reflects the transcriptional activity of SHRs. Our reporter systems also provide a platform for direct assessing and comparing different SHR mutants and variants in their transcriptional activity, which allows for the linking of specific SHR alterations with clinical phenotypes and treatment outcome. Furthermore, our reporter systems are versatile and can be adapted to report the activity of other hormone receptors such as mineralocorticoid receptor (MR), progesterone receptor (PR), and thyroid hormone receptor (THR), by replacing the hormone responsive promoter in the pcDNA3.1(-)-4×ARE-Fluc-ARRluc vector with mineralocorticoid receptor elements (MREs), progesterone receptor elements (PREs), or thyroid hormone receptor elements (THRs), and replacing the AR gene with $M R$, PR, or THR.

Our sensitive assay systems have revealed functional alterations in $\mathrm{AR}, \mathrm{GR}$ or $\mathrm{ER} \alpha$ caused by genetic mutations or splicing variations, with many results being consistent with previous studies $(6,9,31,32,43)$. However, there are also discrepancies between our results and previous reports. For example, in our study ER $\alpha$ variants including TADDI, ER $\alpha 36$, and $\mathrm{ER} \alpha 46$ displayed higher transactivation ability compared with ER $\alpha$-wt in the presence of DES (Figure 3), but these variants displayed distinct transcriptional activities in other cell lines $(51,52)$. These discrepancies could result from the different cell lines used which may express different levels of co-regulators of SHRs. Some ER $\alpha$ mutants including E380Q, S463P, L469V, L536H, L536R, Y537C, and Y537D were reported to have an modest increase in transactivation activity in the absence of estradiol (E2), compared to $\mathrm{ER} \alpha$-wt $(19,34,53)$. In our study, although some of these mutants showed the same trend as previous studies, the changes in transcriptional activity are not statistically significant (Figure 3). We hypothesized that some variants or mutations may be more effective than ER $\alpha$-wt in ligand independent activation, but they are not the main causes of disease progression. In addition to transcriptional activity, mutations or splicing variations in SHRs may also cause changes in their half-life and sensitivity to promiscuous agonists, and crosstalk with other factors. Future work is needed to further improve reporter systems for SHRs in order to better inform disease mechanisms and treatment.

\section{DATA AVAILABILITY STATEMENT}

The datasets generated for this study are available on request to the corresponding author.

\section{AUTHOR CONTRIBUTIONS}

FX, ML, and LW conceived the study and designed the experiments. HJ, YL, MT, ZL, and LZ performed the experiments. FS, YZ, JZ, and $\mathrm{HL}$ made clinical validation. LL, BA, and JM collected clinical interpterion. $\mathrm{HJ}$ and FX 
wrote the manuscript. All authors read and approved the final manuscript.

\section{FUNDING}

This work was supported by the CAMS Innovation Fund for Medical Sciences (2018-I2M-1-002), the National Key Research and Development Program of China (Grant 2018YFC2002202 \& 2017YFC0840102), National Science and Technology Major Project for Significant New Drugs Creation (2017ZX09304026), National Natural Science Foundation of China (Grant 81902618 \& 81871107), the Fundamental Research Funds for the Central Universities (Grant 3332019120).

\section{REFERENCES}

1. DeRijk RH, Schaaf M, De Kloet ER. Glucocorticoid receptor variants: clinical implications. J Steroid Biochem Mol Biol. (2002) 81:103-22. doi: 10.1016/S0960-0760(02)00062-6

2. Nitsche EM, Hiort O. The molecular basis of androgen insensitivity. Hormone Res. (2000) 54:327-33. doi: 10.1159/000053282

3. Jia S, Miedel MT, Ngo M, Hessenius R, Chen N, Wang P, et al. Clinically observed estrogen receptor alpha mutations within the ligand-binding domain confer distinguishable phenotypes. Oncology. (2018) 94:176-89. doi: $10.1159 / 000485510$

4. Holohan C, Van Schaeybroeck S, Longley DB, Johnston PG. Cancer drug resistance: an evolving paradigm. Nat Rev Cancer. (2013) 13:714-26. doi: $10.1038 / \mathrm{nrc} 3599$

5. Yoshida $T$, Kinoshita H, Segawa $T$, Nakamura E, Inoue $T$, Shimizu $\mathrm{Y}$, et al. Antiandrogen bicalutamide promotes tumor growth in a novel androgen-dependent prostate cancer xenograft model derived from a bicalutamide-treated patient. Cancer Res. (2005) 65:9611-6. doi: 10.1158/0008-5472.CAN-05-0817

6. Hu R, Dunn TA, Wei S, Isharwal S, Veltri RW, Humphreys E, et al. Ligandindependent androgen receptor variants derived from splicing of cryptic exons signify hormone-refractory prostate cancer. Cancer Res. (2009) 69:1622. doi: 10.1158/0008-5472.CAN-08-2764

7. Sun S, Sprenger CCT, Vessella RL, Haugk K, Soriano K, Mostaghel EA, et al. Castration resistance in human prostate cancer is conferred by a frequently occurring androgen receptor splice variant. J Clin Investig. (2010) 120:271530. doi: $10.1172 /$ jci41824

8. Hu DG, Hickey TE, Irvine C, Wijayakumara DD, Lu L, Tilley WD, et al. Identification of androgen receptor splice variant transcripts in breast cancer cell lines and human tissues. Hormones Cancer. (2014) 5:61-71. doi: 10.1007/s12672-014-0171-4

9. Yang X, Guo Z, Sun F, Li W, Alfano A, Shimelis H, et al. Novel membraneassociated androgen receptor splice variant potentiates proliferative and survival responses in prostate cancer cells. J Biol Chem. (2011) 286:36152-60. doi: 10.1074/jbc.M111.265124

10. Watson PA, Chen YF, Balbas MD, Wongvipat J, Socci ND, Viale A, et al. Constitutively active androgen receptor splice variants expressed in castration-resistant prostate cancer require full-length androgen receptor. Proc Natl Acad Sci USA. (2010) 107:16759-65. doi: 10.1073/pnas.1012443107

11. Hurley DM, Accili D, Stratakis CA, Karl M, Vamvakopoulos N, Rorer E, et al. Point mutation causing a single amino acid substitution in the hormone binding domain of the glucocorticoid receptor in familial glucocorticoid resistance. J Clin Investig. (1991) 87:680-6. doi: 10.1172/JCI115046

12. Kohli M, Ho Y, Hillman DW, Van Etten JL, Henzler C, Yang R, et al. Androgen receptor variant AR-V9 is coexpressed with AR-V7 in prostate cancer metastases and predicts abiraterone resistance. Clin Cancer Res. (2017) 23:4704-15. doi: 10.1158/1078-0432.CCR-17-0017

13. Kallio HM, Hieta R, Brofeldt A, Annala M, Kivinummi K, Tammela TL, et al. Abstract 1802: Constitutively active androgen receptor splice

\section{ACKNOWLEDGMENTS}

The authors would like to acknowledge the valuable suggestions made by Jörg Klug at Justus-Liebig University, Giessen, Germany; and Zhongsheng You at Washington University in St. Louis.

\section{SUPPLEMENTARY MATERIAL}

The Supplementary Material for this article can be found online at: https://www.frontiersin.org/articles/10.3389/fendo. 2020.00167/full\#supplementary-material

variants AR-V3, AR-V7 and AR-V9 are co-expressed in castrationresistant prostate cancer metastases. Cancer Res. (2018) 78:1802-1802. doi: 10.1158/1538-7445.am2018-1802

14. Bohl CE, Gao W, Miller DD, Bell CE, Dalton JT. Structural basis for antagonism and resistance of bicalutamide in prostate cancer. Proc Natl Acad Sci USA. (2005) 102:6201-6. doi: 10.1073/pnas.05003 81102

15. Fenton MA, Shuster TD, Fertig AM, Taplin ME, Kolvenbag G, Bubley GJ, et al. Functional characterization of mutant androgen receptors from androgenindependent prostate cancer. Clin Cancer Res. (1997) 3:1383-8.

16. Korpal M, Korn JM, Gao X, Rakiec DP, Ruddy DA, Doshi $S$, et al. An F8761 mutation in androgen receptor confers genetic and phenotypic resistance to MDV3100 (Enzalutamide). Cancer Discov. (2013) 3:1030-43. doi: 10.1158/2159-8290.CD-1 3-0142

17. Veldscholte J, Berrevoets CA, Ris-Stalpers C, Kuiper GGJM, Jenster G, Trapman J, et al. A mutation in the ligand binding domain of the androgen receptor of human INCaP cells affects steroid binding characteristics and response to anti-androgens. J Steroid Biochem Mol Biol. (1992) 41:665-9. doi: 10.1016/0960-0760(92)90401-4

18. Robinson DR, Wu Y-M, Vats P, Su F, Lonigro RJ, Cao X et al. Activating ESR1 mutations in hormone-resistant metastatic breast cancer. Nat Genet. (2013) 45:1446-51. doi: 10.1016/j.clinph.2009.08.004.Neurophysiologic

19. Toy W, Weir H, Razavi P, Lawson M, Goeppert AU, Mazzola $\mathrm{AM}$, et al. Activating ESR1 mutations differentially impact the efficacy of ER antagonists. Cancer Discov. (2017) 7:277-87. doi: 10.1158/2159-8290.CD-15-1523.Activating

20. Chandarlapaty S, Chen D, He W, Sung P, Samoila A, You D, et al. Prevalence of ESR1 mutations in cell-free DNA and outcomes in metastatic breast cancer: a secondary analysis of the BOLERO-2 clinical trial. Hepatology. (2017) 63:965-82. doi: 10.1002/hep.28382.MACROPHAGE

21. Ruiz M, Lind U, Gåfvels M, Eggertsen G, Carlstedt-Duke J, Nilsson L, et al. Characterization of two novel mutations in the glucocorticoid receptor gene in patients with primary cortisol resistance. Clin Endocrinol. (2001) 55:363-71. doi: 10.1046/j.1365-2265.2001.01323.x

22. Malchoff DM, Brufsky A, Reardon G, McDermott P, Javier EC, Bergh CH, et al. A mutation of the glucocorticoid receptor in primary cortisol resistance. J Clin Investig. (1993) 91:1918-25. doi: 10.1172/JCI116410

23. Streicher W, Zengerling F, Laschak M, Weidemann W, Höpfner M, Schrader AJ, et al. AR-Q640X, a model to study the effects of constitutively active Cterminally truncated AR variants in prostate cancer cells. World J Urol. (2012) 30:333-9. doi: 10.1007/s00345-012-0842-0

24. Zhan Y, Zhang G, Wang X, Qi Y, Bai S, Li D, et al. Interplay between cytoplasmic and nuclear androgen receptor splice variants mediate castration resistance. Mol Cancer Res. (2017) 15:59-68.

25. Jagla M, Fève M, Kessler P, Lapouge G, Erdmann E, Serra S, et al. A splicing variant of the androgen receptor detected in a metastatic prostate cancer exhibits exclusively cytoplasmic actions. Endocrinology. (2007) 148:4334-43. doi: 10.1210/en.2007-0446 
26. Ahrens-Fath I, Politz O, Geserick C, Haendler B. Androgen receptor function is modulated by the tissue-specific AR45 variant. FEBS J. (2005) 272:74-84. doi: 10.1111/j.1432-1033.2004.04395.x

27. Kaphingst KA, Persky S, Lachance C. A snapshot of the expression signature of androgen receptor splicing variants and their distinctive transcriptional activities. Prostate. (2010) 14:384-99. doi: 10.1080/10810730902873927.Testing

28. Dehm SM, Schmidt LJ, Heemers HV, Vessella RL, Tindall DJ. Splicing of a novel AR exon generates a constitutively active androgen receptor that mediates prostate cancer therapy resistance. Cancer Res. (2009) 68:5469-77. doi: 10.1158/0008-5472.CAN-08-0594.Splicing

29. Koochekpour S. Androgen receptor signaling and mutations in prostate cancer. Asian J Androl. (2010) 12:639-57. doi: 10.1038/aja.2010.89

30. Herynk MH, Fuqua SAW. Estrogen receptor mutations in human disease. Endocrine Rev. (2004) 25:869-98. doi: 10.1210/er.2003-0010

31. Fuqua SAW, Wolf DM. Molecular aspects of estrogen receptor variants in breast cancer. Breast Cancer Res Treat. (1995) 35:233-41. doi: 10.1007/BF00665974

32. Fuqua SAW, Klotz DM, Hill SM. Expression of a constitutively active estrogen receptor variant in the estrogen receptor-negative BT-20 human breast cancer cell line. Cancer Res. (1993) 53:5934-9.

33. Bollig A, Miksicek RJ. An estrogen receptor- $\alpha$ splicing variant eediates both positive and negative effects on gene transcription. Mol Endocrinol. (2000) 14:634-49. doi: 10.1210/mend.14.5.0460

34. Jeselsohn R, Yelensky R, Buchwalter G, Frampton G, Meric-Bernstam F, Gonzalez-Angulo AM, et al. Emergence of constitutively active estrogen receptor- $\alpha$ mutations in pretreated advanced estrogen receptor-positive breast cancer. Clin Cancer Res. (2014) 20:1757-67. doi: 10.1158/1078-0432.CCR-13-2332

35. Schiavon G, Hrebien S, Garcia-Murillas I, Cutts RJ, Pearson A, Tarazona N, et al. Analysis of ESR1 mutation in circulating tumor DNA demonstrates evolution during therapy for metastatic breast cancer. Sci Transl Med. (2015) 7:313ra182. doi: 10.1126/scitranslmed.aac7551

36. Takeshita T, Yamamoto Y, Yamamoto-Ibusuki M, Tomiguchi M, Sueta A, Murakami K, et al. Analysis of ESR1 and PIK3CA mutations in plasma cell-free DNA from ER-positive breast cancer patients. Oncotarget. (2017) 8:52142-55. doi: 10.18632/oncotarget.18479

37. Spoerke JM, Gendreau S, Walter K, Qiu J, Wilson TR, Savage H, et al. Heterogeneity and clinical significance of ESR1 mutations in ER-positive metastatic breast cancer patients receiving fulvestrant. Nat Commun. (2016) 7:11579. doi: $10.1038 /$ ncomms 11579

38. Fanning SW, Mayne CG, Dharmarajan V, Carlson KE, Martin TA, Novick SJ, et al. Estrogen receptor alpha somatic mutations Y537S and D538G confer breast cancer endocrine resistance by stabilizing the activating function-2 binding conformation. eLife. (2016) 5:1-25. doi: 10.7554/eLife.12792

39. Kozaci DL, Chernajovsky Y, Chikanza IC. The differential expression of corticosteroid receptor isoforms in corticosteroid-resistant and sensitive patients with rheumatoid arthritis. Rheumatology. (2007) 46:579-85. doi: 10.1093/rheumatology/kel276

40. Shahidi H, Vottero A, Stratakis CA, Taymans SE, Karl M, Longui CA, et al. Imbalanced expression of the glucocorticoid receptor isoforms in cultured lymphocytes from a patient with systemic glucocorticoid resistance and chronic lymphocytic leukemia. Bioche Biophys Res Commun. (1999) 254:55965. doi: 10.1006/bbrc.1998.9980

41. McBeth L, Nwaneri AC, Grabnar M, Demeter J, Nestor-Kalinoski A, Hinds TD. Glucocorticoid receptor beta increases migration of human bladder cancer cells. Oncotarget. (2016) 7:27313-24. doi: 10.18632/oncotarget.8430

42. Beger C, Gerdes K, Lauten M, Tissing WJE, Fernandez-Munoz I, Schrappe $\mathrm{M}$, et al. Expression and structural analysis of glucocorticoid receptor isoform gamma in human leukaemia cells using an isoform-specific realtime polymerase chain reaction approach. Brit J Haematol. (2003) 122:245-52. doi: 10.1046/j.1365-2141.2003.04426.x

43. Wu I, Shin SC, Cao Y, Bender IK, Jafari N, Feng G, et al. Selective glucocorticoid receptor translational isoforms reveal glucocorticoidinduced apoptotic transcriptomes. Cell Death Dis. (2013) 4:1-12. doi: $10.1038 /$ cddis.2012.193

44. Roberts ML, Kino T, Nicolaides NC, Hurt DE, Katsantoni E, Sertedaki A, et al. A novel point mutation in the DNA-binding domain (DBD) of the human glucocorticoid receptor causes primary generalized glucocorticoid resistance by disrupting the hydrophobic structure of its DBD. J Clin Endocrinol Metab. (2013) 98:790-5. doi: 10.1210/jc.2012-3549

45. Nicolaides NC, Geer EB, Vlachakis D, Roberts ML, Psarra AMG, Moutsatsou P, et al. A novel mutation of the hGR gene causing Chrousos syndrome. Eu J Clin Investig. (2015) 45:782-91. doi: 10.1111/eci. 12470

46. Al Argan R, Saskin A, Yang JW, D’Agostino MD, Rivera J. Glucocorticoid resistance syndrome caused by a novel $\mathrm{nr} 3 \mathrm{cl}$ point mutation. Endocrine J. (2018) 65:1139-46. doi: 10.1507/endocrj.EJ18-0135

47. Vottero A, Kino T, Combe H, Lecomte P, Chrousos GP. A novel, C-terminal dominant negative mutation of the GR causes familial glucocorticoid resistance through abnormal interactions with p160 steroid receptor coactivators. J Clin Endocrinol Metab. (2002) 87:2658-67. doi: 10.1210 /jcem.87.6.8520

48. Van Rossum EFC, Lamberts SWJ. Polymorphisms in the glucocorticoid receptor gene and their associations with metabolic parameters and body composition. Recent Prog Hormone Res. (2004) 59:333-57. doi: $10.1210 /$ rp.59.1.333

49. Cihan MK, Karabulut HG, Kutlay NY, Ruhi HI, Tükün A, Olcay L Association between N363S and bcll polymorphisms of the glucocorticoid receptor gene $(\mathrm{NR} 3 \mathrm{C} 1)$ and glucocorticoid side effects during childhood acute lymphoblastic leukemia treatment. Turkish J Hematol. (2017) 34:151-8. doi: 10.4274/tjh.2016.0253

50. Steinestel J, Luedeke M, Arndt A, Schnoeller TJ, Schrader AJ. Detecting predictive androgen receptor modifications in circulating prostate cancer cells. Oncotarget. (2015) 23:1-11. doi: 10.18632/oncotarget.3925

51. Ishunina TA, Sluiter AA, Swaab DF, Verwer RWH. Transcriptional activity of human brain estrogen receptor- $\alpha$ splice variants: evidence for cell type-specific regulation. Brain Res. (2013) 1500:1-9. doi: 10.1016/j.brainres.2012.12.050

52. Figtree GA, McDonald D, Watkins H, Channon KM. Truncated estrogen receptor $\alpha 46-\mathrm{kDa}$ isoform in human endothelial cells: relationship to acute activation of nitric oxide synthase. Circulation. (2003) 107:120-6. doi: 10.1161/01.CIR.0000043805.11780.F5

53. Toy W, Shen Y, Won H, Green B, Sakr RA, Will M, et al. ESR1 ligandbinding domain mutations in hormone-resistant breast cancer. Nat Genet. (2013) 45:1439-45. doi: 10.1038/ng.2822

Conflict of Interest: The authors declare that the research was conducted in the absence of any commercial or financial relationships that could be construed as a potential conflict of interest.

Copyright (c) $2020 \mathrm{Ji}$, Li, Liu, Tang, Zou, Su, Zhang, Zhang, Li, Li, Ai, Ma, Wang, Liu and Xiao. This is an open-access article distributed under the terms of the Creative Commons Attribution License (CC BY). The use, distribution or reproduction in other forums is permitted, provided the original author(s) and the copyright owner(s) are credited and that the original publication in this journal is cited, in accordance with accepted academic practice. No use, distribution or reproduction is permitted which does not comply with these terms. 